\title{
O compartilhamento de significado na aula de Física e a atuação do interlocutor de Língua Brasileira de Sinais
}

\author{
The sharing of meaning in physics class and the work of the \\ interlocutor of Brazilian Sign Language
}

Márlon Pessanha ${ }^{1}$ • Sabrina Cozendey ${ }^{2}$ • Diego Marceli Rocha ${ }^{3}$

\begin{abstract}
Resumo: A inclusão dos alunos com deficiência auditiva e dos alunos com surdez nas escolas brasileiras exorta por pesquisas que abordem, por exemplo, a diversidade linguística em ambientes educacionais bilíngues. Apresentamos um estudo em que buscamos verificar o compartilhamento de significados entre a Língua Portuguesa e a Libras para enunciados explicativos sobre dois conceitos fundamentais no ensino de Física: velocidade e aceleração. Tais enunciados foram apresentados por um interlocutor de Libras atuante em aulas de Física. Considerando algumas ideias presentes nas teorias de Bakhtin, verificamos as significações assumidas pelos principais sinais apresentados pelo interlocutor. Verificamos que os sinais apresentados pelo interlocutor podem assumir significados diversos, o que, em alguns casos, divergem do significado físico-científico. Percebemos que cabe ao interlocutor reconhecer os sinais mais adequados, mas tal reconhecimento passa por um entendimento correto do conteúdo de física que será interpretado, o que remete a uma necessária preparação conjunta com o professor.
\end{abstract}

Palavras-chave: Inclusão escolar. Deficiência auditiva. Surdez. LIBRAS. Ensino de Física.

\begin{abstract}
The inclusion of students with hearing impairment and students with deafness in Brazilian schools calls for research, for example, involving linguistic diversity in bilingual educational environments. We present a study in which we seek to verify the sharing of meanings between the Portuguese Language and the Brazilian Sign Language for explanation of two fundamental concepts in physics teaching: velocity and acceleration. The explanations were presented by an interlocutor of Libras who worked in physics classes. Using some ideas of Bakhtin, we check the significance assumed by the main signs presented by the interlocutor. We verified that the signals presented by interlocutor may assume various meanings, in some cases, different from the scientific meaning. We note that the interlocutor needs to recognize the most appropriate signs, but such recognition needs a correct understanding of the content of physics, which requires joint preparation with the teacher.
\end{abstract}

Keywords: School inclusion. Hearing impairment. Deafness. Brazilian Sign Language. Physics education.

\footnotetext{
${ }^{1}$ Departamento de Metodologia de Ensino, Universidade Federal de São Carlos (UFSCar), Rod. Washington Luis, km 235, CEP 13565-905, São Carlos, SP, Brasil. E-mail: <pessanha@ufscar.br>

${ }^{2}$ Departamento de Psicologia, Universidade Federal de São Carlos (UFSCar), São Carlos, SP, Brasil.

${ }^{3}$ Faculdade de Educação, Universidade de São Paulo (USP), São Paulo, SP, Brasil.
} 


\section{Introdução}

Questões relativas à linguagem têm direcionado diversas pesquisas em ensino de ciências. Algumas dessas questões tratam das dificuldades que emergem das diferenças entre a linguagem cotidiana e a linguagem científica que é tratada nas disciplinas escolares. Tais diferenças residem nos divergentes sentidos que determinados termos de uma mesma língua podem assumir quando utilizados em diferentes contextos. Na pesquisa em ensino de Física, tais diferenças são bem conhecidas, tendo como alguns dos exemplos mais clássicos os diferentes significados assumidos para os termos calor e peso (SILVA; LABURÚ; NARDI, 2008; TEIXEIRA; PACCA, 1994). O conhecimento prévio dos alunos, que é relevante na atribuição de significados, origina-se na experiência pessoal do indivíduo em meio ao seu contexto sociocultural. É no convívio social, histórico e cultural que o indivíduo interioriza signos linguísticos, gestuais, sonoros, entre outros; os quais integrarão o conjunto de ideias que estamos chamando de conhecimento prévio.

Um diálogo promovido em uma aula de ciências está impregnado de signos que podem apresentar significados diferentes para os indivíduos envolvidos. Se, para falantes de uma mesma língua, existe esta dificuldade, o que dizer sobre um processo em que as pessoas envolvidas possuem não somente diferenças de significado para os signos linguísticos, mas, também, meios linguísticos (línguas) diferentes para se comunicar? Tal indagação parece, em um primeiro momento, distante da realidade; no entanto, se olharmos mais atentamente para o contexto escolar atual do Brasil, nos deparamos com um processo que corre neste sentido: a inserção de alunos com deficiência auditiva e de alunos com surdez na sala de aula da escola regular.

\section{Inclusão escolar e a Língua Brasileira de Sinais}

A educação inclusiva é um paradigma da educação que pressupõe uma escola que seja capaz de ensinar a alunos de diferentes culturas e raças, e de diferentes necessidades educacionais. Trata-se de uma ação política, social, cultural e pedagógica que busca defender o direito de todos os alunos de aprenderem juntos, sem nenhum tipo de discriminação (BRASIL, 2007).

Neste sentido as escolas inclusivas devem:

[...] reconhecer as diferentes necessidades de seus alunos e responder a elas, adaptar-se aos diferentes estilos e ritmos de aprendizagem dos alunos, garantir um ensino de qualidade por meio de um programa de estudos apropriado, uma boa organização escolar, um uso criterioso dos recursos e parcerias com as comunidades. Deveria existir, de fato, uma contínua prestação de serviços e apoio para satisfazer às contínuas necessidades especiais que surgem na escola. (UNESCO, 1994, p. 1112 , tradução nossa)

Como a diversidade cultural existente no Brasil, de certa forma, ameniza as diferenças étnicas que, para outros países, têm sido o principal foco da inclusão, em nosso país, a inclusão escolar, normalmente, é associada à inclusão de alunos com deficiência nas escolas regulares.

A inclusão de pessoas com deficiência tem sido assumida como um direito fundamental em muitos documentos nacionais e internacionais; sendo alguns dos mais recentes: 
a Constituição Federal de 1988 (BRASIL, 1988); a Declaração Mundial sobre Educação para Todos (UNESCO, 1990); a Declaração de Salamanca (UNESCO, 1994); a Lei de Diretrizes e Bases da Educação Nacional (BRASIL, 1996); a Convenção da Guatemala de 1999, ratificada pelo Decreto Presidencial no 3.956 (BRASIL, 2001); a Convenção dos Direitos das Pessoas com Deficiência, ratificada e incorporada à constituição como Decreto Legislativo no 186/2008 (BRASIL, 2008); a Política Nacional de Educação Especial na Perspectiva da Educação Inclusiva (BRASIL, 2007), entre outros dispositivos legais.

Vale destacar que a inclusão escolar não se resume à inserção de alunos com necessidades especiais em uma turma de uma escola regular. Mais do que isso, conforme afirma Rodrigues (2006), a inclusão envolve a rejeição da exclusão presencial e acadêmica. Isto é, o aluno deve estar presente na sala de aula da escola regular, mas, também, deve ter condições de aprender em conjunto com os demais alunos da turma. Somente assim se efetiva a inclusão escolar.

Entre os alunos a serem atendidos em uma escola regular, estão aqueles que possuem a sua capacidade auditiva reduzida ou mesmo a ausência da audição. Alguns destes alunos podem ser definidos como pessoas com deficiência auditiva, enquanto outros podem ser definidos como surdos. Segundo Gesser (2009), tais termos se referem, não ao grau de audição da pessoa, mas, sim, a uma identidade cultural relacionada com o uso da oralidade, com o convívio social, e com o uso da língua de sinais. Em uma definição de natureza sociocultural, a autora afirma que, enquanto a pessoa com deficiência auditiva geralmente se comunica oralmente, possui um resíduo auditivo que é potencializado com aparelhos auditivos, e prefere conviver com ouvintes, o surdo é aquele que assume, e de fato tem, a língua de sinais como primeira língua, além de preferir o convívio com outras pessoas surdas.

Vale destacar que tal definição dos termos "deficiência auditiva" e "surdez" não é a única. Existem, por exemplo, as definições de origem médica, as quais classificam a surdez e a deficiência auditiva em função do período de aquisição, da causa, do tipo de perda auditiva e quanto ao grau de comprometimento em escutar sons (BRASIL, 2006). Independente da classificação, ambos os termos são utilizados ao se discutir a inclusão, tanto na esfera política como na esfera educacional. Neste sentido, optamos, no presente artigo, por utilizar ambos os termos, porém reconhecendo que se referem a grupos de pessoas com características próprias e com diferenças entre si.

A deficiência auditiva e a surdez, uma vez que prejudicam um dos principais sentidos humanos, a audição, diminuem a percepção dos sons e afetam a capacidade de comunicação por meio da linguagem oral (COSTA, 2003). A deficiência auditiva e a surdez podem ser adquiridas ao longo da vida por problemas que ocorram em alguma das partes da orelha ${ }^{4}$ ou podem ocorrer devido a algum problema congênito.

No cotidiano em que a linguagem oral é utilizada como uma das principais formas de transmissão de ideias e conhecimentos, a comunicação se torna a grande dificuldade que uma pessoa com surdez e uma pessoa com deficiência auditiva severa ou profunda encontram. No entanto, uma mensagem direcionada a um surdo ou a uma pessoa com deficiência auditiva severa

\footnotetext{
${ }^{4} \mathrm{O}$ termo "orelha" é utilizado conforme a terminologia anatômica adotada pela Sociedade Brasileira de Anatomia.
} 
ou profunda pode ser compreendida visualmente a partir de alguns meios, a destacar-se: a percepção dos gestos mímicos ou linguísticos (língua de sinais) e a leitura labial ou orofacial. Estes meios de comunicação exploram a capacidade de leitura do mundo por vias visuais, capacidade esta especialmente importante para as pessoas com deficiência auditiva e para as pessoas com surdez, e que deve ser considerada no processo de escolarização destes.

Na prática educativa, o uso dos gestos linguísticos presentes em uma língua de sinais, como é o caso da Língua Brasileira de Sinais (LIBRAS), é uma forma de privilegiar a comunicação visual-motora acessível aos alunos com deficiência auditiva e aos alunos com surdez. A Libras, forma de comunicação e expressão com um sistema linguístico de natureza visual-motora e estrutura gramatical própria, permite a transmissão de ideias e fatos e constitui-se como uma língua, assim reconhecida oficialmente no Brasil, de forma legal, por meio da Lei no 10.436 de 24 de abril de 2002 (BRASIL, 2002). Com o reconhecimento oficial da Libras como língua, a partir de sua regulamentação no processo inclusivo (BRASIL, 2005), e uma vez definida a Política Nacional de Educação Especial na Perspectiva da Educação Inclusiva (BRASIL, 2007), o aluno com deficiência auditiva e o aluno com surdez adquiriram o direito a estudar em escolas regulares e ter o auxílio de intérpretes em sua educação, sendo esta de caráter bilíngue.

O decreto presidencial No 5.626 de 22 de dezembro de 2005 (BRASIL, 2005), define, em seu Capítulo V, as responsabilidades do poder público em oferecer cursos superiores específicos de formação de tradutor e intérprete de Libras. No entanto, o decreto prevê um período de 10 anos nos quais, não havendo profissionais com a titulação exigida, outros profissionais ouvintes de nível Superior e Médio poderiam realizar a interpretação simultânea e consecutiva em Libras e na Língua Portuguesa em instituições educacionais federais de nível Médio e Superior, desde que tivessem competência e fluência em Libras e fossem aprovados em um exame de proficiência promovido pelo Ministério da Educação.

O decreto presidencial, no entanto, não é o dispositivo legal que regulamenta a profissão de tradutor e intérprete de Libras (BRASIL, 2010a). O decreto se restringe a definir obrigações específicas da União e das instituições federais, e em sugerir os esforços que deveriam ser adotados pelas instituições públicas e privadas dos sistemas de ensino federal, estadual, municipal e do Distrito Federal. A regulamentação da profissão de tradutor e intérprete de Libras é regida pela Lei $N^{o} 12.319$ de $1^{\circ}$ de setembro de 2010 (BRASIL, 2010b), a qual prevê a formação de tradutores e intérpretes de Libras em nível Médio, por meio de: cursos de formação profissional, cursos de extensão universitária e cursos de formação continuada. A lei também reforça a responsabilidade da União em promover, anualmente, o exame nacional de proficiência em Tradução e Interpretação de Libras - Língua Portuguesa, até 22 de dezembro de 2015, que é quando se encerra o período de dez anos de adequação formativa dos profissionais intérpretes das instituições federais.

Assim, segundo a legislação vigente, o tradutor e intérprete de Libras seria um profissional formado para este fim, em nível Médio ou Superior, que atuaria na educação regular de forma a assegurar, aos alunos surdos ou com deficiência auditiva, o acesso à comunicação, à informação e à educação.

Apesar de transcorridos quase dez anos do decreto presidencial No 5.626 , há ainda uma carência de intérpretes de Libras formados e habilitados para a atuação na educação regular. Assim, governos estaduais e municipais têm buscado alternativas para oferecer aos alunos surdos e aos alunos com deficiência auditiva meios para que possam acompanhar as aulas. Para 
suprir a carência de intérpretes, a Secretaria de Educação do Estado de São Paulo, a partir da resolução no 38 de 2009, criou a função de interlocutor de Libras-Língua Portuguesa (SÃO PAULO, 2009). Conforme a resolução, o interlocutor de Libras-Língua Portuguesa (ou, simplesmente, interlocutor de Libras) deve ter formação Superior em algum curso de Licenciatura Plena, e atender a uma entre quatro tipos de titulação, entre as quais há o curso de Libras com, no mínimo, cento e vinte horas.

O presente artigo envolve um estudo de caso realizado com a participação de um interlocutor de Libras atuante em aulas de Física do Ensino Médio do estado de São Paulo. Neste artigo, buscamos refletir sobre o papel do interlocutor de Libras, e sobre como possíveis diferenças de significado entre os termos linguísticos da língua portuguesa e da Libras podem interferir na aprendizagem de conceitos de Física.

\section{Estudo de caso: as escolhas do interlocutor de Libras e a sua preparação}

O estudo que aqui apresentamos foi realizado para investigar o compartilhamento de significado entre o que se apresenta em uma aula de Física e o que é apresentado em Libras por um interlocutor. A partir de um estudo de caso, buscamos levantar alguns dados que nos permitiram inferir sobre a potencialidade da aprendizagem em um contexto bilíngue envolvendo a língua Portuguesa e a Língua Brasileira de Sinais (Libras).

O estudo de caso foi realizado com a participação de um interlocutor de Libras, o qual, no período de realização da pesquisa, atuava nesta função em sala de aula há um ano, em uma escola da rede pública do estado de São Paulo, em turmas de Ensino Médio, na modalidade de Educação de Jovens e Adultos (EJA).

O interlocutor participante, que era licenciado em História, mas sem nunca ter atuado profissionalmente como professor, possuía pouco tempo de formação em Libras. Ele havia concluído, dois anos antes, um curso de Libras com carga horária superior a cento e oitenta horas, e, no período de realização deste estudo, cursava uma pós-graduação lato sensu em Libras, direcionada à atuação em sala de aula da educação regular.

Durante o estudo, foi solicitado, ao interlocutor, que apresentasse, em Libras, dois enunciados explicativos sobre os conceitos físicos de velocidade e aceleração. Estes conceitos estão relacionados a fenômenos presentes no dia a dia: os alunos, em geral, incluindo aqueles que possuem uma deficiência auditiva e aqueles com surdez, experimentam, em seu cotidiano, situações envolvendo deslocamentos, variação de tempo e mudança de velocidade. Pela proximidade com as situações cotidianas, e considerando que tais conceitos são basilares no estudo da Física, em especial da mecânica, acreditamos que enunciados sobre os conceitos de velocidade e aceleração apresentam-se como particularmente férteis para o estudo que propomos, o qual consiste em analisar o compartilhamento de significado no ensino de Física em contextos bilíngues.

Os enunciados considerados possuem termos comumente utilizados na explicação dos conceitos de velocidade e aceleração. Eles foram elaborados neste estudo, mas são semelhantes aos apresentados em livros didáticos e presentes, muitas vezes, no discurso do professor de Física. São eles:

- Velocidade se refere à variação da posição de um corpo em função do tempo. Ao se movimentar de uma posição à outra um corpo apresentará um deslocamento. Velocidade é quanto o corpo se desloca por unidade de tempo. 
- Aceleração se refere à variação da velocidade de um corpo em função do tempo. Um corpo pode aumentar ou diminuir sua velocidade durante um movimento. Aceleração é quanto a velocidade do corpo se altera por unidade de tempo.

Conforme definido no planejamento do estudo, o interlocutor de Libras apresentou ambos os enunciados em dois momentos distintos: logo após conhecer os enunciados, e após uma semana.

Com a apresentação do enunciado em um primeiro momento, buscamos aproximar a interpretação em Libras a uma situação de sala de aula em que o interlocutor toma conhecimento do que deve interpretar em tempo real. Assim, o primeiro momento se assemelha a situações em que não há uma preparação conjunta com o professor, o que, segundo o próprio interlocutor participante, era uma situação frequente. Segundo ele, dificilmente era possível se reunir com um professor para discutir previamente o conteúdo, o que poderia lhe auxiliar em sua preparação para interpretar a aula.

O segundo momento, em que o interlocutor teve um período de uma semana para analisar os enunciados para novamente interpretá-los, permitiu uma aproximação à situação em que uma preparação poderia ocorrer com ou sem o auxílio de algum professor. O interlocutor pôde, neste intervalo de uma semana, verificar os conceitos de Física que deveria interpretar e consultar algum professor de Física se julgasse necessário, além, é claro, de melhor selecionar os sinais em Libras correspondentes aos conceitos físicos envolvidos. Vale destacar que, logicamente, uma preparação conjunta entre interlocutor e professor não consiste em uma transferência de enunciados que serão ditos em sala de aula, afinal, nenhuma preparação de professor consiste em elaborar frases, decorando-as para, posteriormente, falar em aula. A preparação conjunta entre interlocutor e professor consistiria em, inicialmente, o interlocutor tomar conhecimento do conteúdo que será abordado, para, em seguida, esclarecer o conteúdo para melhor interpretá-lo.

As interpretações foram gravadas em vídeo, de forma que fosse possível uma posterior análise que nos permitisse inferir sobre a potencial participação do interlocutor na promoção de um compartilhamento de significados na sala de aula de Física.

\section{A interpretação dos enunciados}

A seguir, transcrevemos os termos na língua portuguesa correlatos aos sinais apresentados pelo interlocutor nos dois momentos, segundo a mesma sequência de sinais apresentada por ele. Ao transcrevermos os sinais relacionados com os conceitos físicos, os identificamos com um número indicado entre parênteses. No Apêndice ao final do artigo, há uma lista com a descrição de como cada sinal é apresentado. Nos dois momentos, o interlocutor também apresentou alguns termos por datilologia, ou seja, com a sequência de sinais referentes a cada letra que compunha a palavra na língua portuguesa. Para estes casos, os termos são transcritos com as letras separadas por hífen. Com o intuito de facilitar a análise, após cada transcrição também apresentamos versões reescritas segundo a estrutura gramatical da língua portuguesa. 


\section{(i) Primeiro momento}

Ao interpretar o enunciado de velocidade, o interlocutor de Libras apresentou a seguinte sequência de sinais:

Aceleração(16) v-a-r-i-a-ç-ã-o posição(1) corpo(2) tempo(9). Movimentar(7) posição(1) deslocamento(6). Aceleração(16) corpo(2) deslocamento(6) tempo(9).

O sinal 6 pode se referir ao substantivo "deslocamento" ou a sua forma verbal "deslocar". Considerando isto e em uma aproximação segundo a estrutura gramatical da língua portuguesa, a sequência de sinais apresentados pelo interlocutor poderia corresponder a:

A aceleração variação da posição do corpo no tempo. Ao movimentar posição, deslocamento. Aceleração, o corpo se desloca no tempo.

Ao interpretar o enunciado sobre aceleração, o interlocutor de Libras apresentou a seguinte sequência de sinais:

Aceleração(16) deslocamento(6) corpo(2) tempo(9). Corpo(2) aumentar diminuir aceleração(16) deslocamento(6). Aceleração(16) aceleração(15) deslocamento(6) tempo(9).

O sinal 15 além de poder ser utilizado para se referir ao termo "aceleração" pode ser utilizado como "aumentar o ritmo". Considerando isto, assim como a possibilidade do sinal 6 poder ser utilizado para representar "deslocamento" ou "deslocar", reescreveríamos o que foi apresentado pelo interlocutor de acordo com a estrutura gramatical da língua portuguesa:

A aceleração deslocamento do corpo no tempo. Um corpo aumenta diminui aceleração no deslocamento. $A$ aceleração aumenta o ritmo do deslocamento no tempo.

$\mathrm{Na}$ interpretação para ambos os enunciados, podemos destacar o uso de um sinal referente ao conceito de aceleração para se referir tanto ao termo "aceleração" como ao termo "velocidade". Ao que parece, o interlocutor não possuía uma compreensão clara sobre os conceitos de velocidade e aceleração. Ressaltamos, no entanto, que até mesmo dicionários de Libras conhecidos amplamente entre os intérpretes possuem certa indefinição em relação aos conceitos de velocidade e aceleração. Isso fica claro mais à frente, quando apresentamos uma breve análise baseada em alguns dicionários de Libras.

Como os termos "aceleração" e "velocidade" representam conceitos basilares da Física e, evidentemente, assumem significados no contexto científico-escolar diferentes do senso comum, a interpretação com um sinal indistinto para os dois termos consiste em um problema grave à adequada compreensão dos conceitos. Podemos afirmar que a apresentação dos conceitos dessa forma dificultaria a aprendizagem dos alunos acompanhados pelo interlocutor. Nesta situação, seria difícil a emersão de um sentido que fosse comum a todos envolvidos no contexto inclusivo, ou seja, que o professor, os alunos com deficiência auditiva, os alunos com surdez e o interlocutor compartilhassem significados semelhantes para os conceitos de velocidade e aceleração apresentados.

Outro ponto a ser destacado é a não-utilização, em alguns casos, do verbo "ser", o que poderia comprometer a compreensão dos enunciados. Como pode ser observado nos trechos em que reescrevemos as interpretações segundo a estrutura gramatical da língua portuguesa, algumas frases não possuem uma clareza, e, em alguns casos, o motivo é a ausência do verbo. Como exemplo, no trecho que interpretamos como "A aceleração deslocamento do corpo no tempo", além de possuir um erro conceitual, a frase se torna ambígua com a ausência do verbo "ser". Além do que apresentamos segundo a língua portuguesa, seria possível interpretar o que 
é apresentado pelo interlocutor como "A aceleração desloca o corpo no tempo", o que estaria igualmente impreciso do ponto de vista conceitual.

Podemos destacar, ainda, alguns outros sinais utilizados pelo interlocutor, como o sinal identificado com o número 1, referente ao termo "posição", e o sinal identificado com o número 2, referente ao termo "corpo". No uso cotidiano da Libras, o sinal 1 é normalmente associado à "postura da pessoa", enquanto o sinal 2 é mais utilizado como "corpo de uma pessoa".

Assim, em ambos os casos, os sinais utilizados possuem um significado mais comum que diverge do significado físico, o que poderia levar à necessidade do uso de sinais sinônimos, ou, mesmo, que se atribuísse o significado físico aos sinais. Vale destacar, no entanto, que o mesmo ocorre no uso da língua portuguesa em situações cotidianas, em que os termos "posição" e "corpo" assumem, respectivamente, os significados "postura de uma pessoa" e "corpo de uma pessoa". No entanto, nos textos científicos e escolares da área de Física, os mesmos termos são utilizados sem que seja necessário o uso de termos sinônimos. Neste sentido, podemos dizer que, em uma situação de sala de aula de Física, a atribuição de significado aos termos seria o mais comum, e poderia ocorrer tanto no uso da língua portuguesa como no uso da Libras.

\section{(ii) Segundo momento}

Ao interpretar pela segunda vez o enunciado sobre velocidade, o interlocutor de Libras apresentou o seguinte enunciado:

Aceleração(15) mais ou menos posição(1) corpo(2) f-u-n-ç-a-o tempo(9). Movimentar(7) deslocamento(6) corpo(2) apresenta d-e-s-l-o-c-a-m-e-n-t-o.Aceleração(16) quando corpo(2) deslocamento(6) u-n-i-d-a-d-e tempo(9).

Considerando o sinal 15 como "aumento de ritmo" e o sinal 6 como "mudar de um lugar para outro" e segundo a estrutura gramatical da língua portuguesa, reescreveríamos a interpretação como:

Aumento de ritmo mais ou menos posição do corpo em função do tempo. Ao movimentar mudando de um lugar a outro, o corpo apresenta um deslocamento. Aceleração quando corpo se desloca por unidade de tempo.

Para o conceito de aceleração, o interlocutor apresentou o enunciado como se segue:

Aceleração(16) mais ou menos aceleração(15) f-u-n-c-a-o tempo(9). Corpo(2) pode aumentar diminuir aceleração(15) movimentar(7). Aceleração(16) quando aceleração(15) corpo(2) muda(6) u-n-i-d-a-d-e tempo(9).

Este corresponde ao seguinte enunciado conforme a estrutura gramatical da língua portuguesa:

A aceleração mais ou menos aumento de ritmo em função do tempo. O corpo pode aumentar diminuir o aumento de ritmo ao movimentar. A aceleração quando o aumento de ritmo do corpo muda por unidade de tempo.

$\mathrm{Na}$ segunda vez em que o interlocutor apresenta os enunciados, ele utiliza um sinal diferente para se referir à aceleração e para se referir à velocidade. Enquanto ele continua, na maioria das vezes, a utilizar o sinal 16 ao se referir ao termo "aceleração", ele passa a utilizar o sinal 15 para se referir ao termo velocidade. A exceção ocorre somente ao final do enunciado sobre velocidade, em que, aparentemente, o interlocutor comete um equívoco ao trocar os sinais.

Apesar de, na maioria das vezes, o interlocutor utilizar um sinal para cada termo, "velocidade" e "aceleração", o sinal escolhido para representar o termo "velocidade", por assumir comumente o significado de "aumentar o ritmo", está mais próximo em significado do conceito de aceleração, e não do conceito de velocidade. Ainda que seja notório que o interlocutor te- 
nha utilizado este sinal para apresentar o termo "velocidade", optamos por apresentá-lo como "aumentar o ritmo" ao reescrevermos o que é interpretado. Assim, buscamos ressaltar não o que o interlocutor pretendia, mas, sim, o que, possivelmente, um aluno acompanhado pelo interlocutor poderia estar compreendendo, considerando o uso mais comum do sinal.

Destacamos, ainda, o frequente uso de um sinal para representar o termo "variação", mas que possui, como significado mais comum, "mais ou menos", que, muitas vezes, assume um sentido de indefinição. Possivelmente, a escolha do interlocutor por este sinal parte de um uso comum deste no cotidiano, em que, em muitas situações, o sinal é utilizado como "mais ou menos" ou como "varia". Entretanto, o termo "variação" empregado nos enunciados possui um significado matemático, e não de indefinição, que o sinal para "mais ou menos" pode sugerir. Assim, podemos dizer que o sinal escolhido apresenta-se como pouco adequado, podendo dificultar o compartilhamento de significado físico.

Como pode ser observado, e que vale ser destacado, no segundo momento de interpretação, o que é apresentado possui uma maior coerência gramatical, ou seja, as frases podem ser mais bem compreendidas, se aproximando dos enunciados propostos. Contudo, o interlocutor ainda opta por não utilizar o verbo "ser", o que poderia gerar problemas na compreensão adequada dos enunciados. Destacamos, ainda, um aparente equívoco de sinais em que, ao invés de utilizar um sinal para o termo "quanto" (relativo à quantidade), o interlocutor utiliza um sinal para o termo "quando" (relativo ao período ou instante em que ocorre um evento).

A seguir, aprofundamos nossa análise sobre o compartilhamento de significado e a mediação do interlocutor na aula de Física. Para isso, tomamos, como um referencial analítico-interpretativo, algumas ideias relacionadas à linguagem apresentadas pelo filósofo russo Mikhail Bakhtin (2006), e, ainda, consideramos, em nossas reflexões, um levantamento de termos apresentados em alguns dicionários de Libras.

\section{Análise interpretativa: compartilhamento de significado e a mediação do interlocutor desde a perspectiva de Bakhtin}

As teorias de Bakhtin envolvem uma visão totalizante em que, ao contrário das ideias dicotômicas existentes em sua época (primeira metade do século XX), a linguagem é vista a partir de um entrelaçamento entre o sujeito e o objeto, e não somente a partir de uma única ótica objetiva ou subjetiva. A linguagem é analisada pela inter-relação entre o sujeito e o contexto social e histórico em que está inserido. Para Bakhtin (2006), a construção do conhecimento se dá pela internalização de discursos alheios em meio às relações interpessoais. Para ele, a interação entre o sujeito e os outros atores presentes no meio social é fundamental, pois sem esta interação o homem: “[...] não mergulha no mundo sígnico, não penetra na corrente da linguagem, não se desenvolve, não realiza aprendizagens, não ascende às funções psíquicas superiores, não forma a sua consciência, enfim, não se constitui como sujeito" (FREITAS, 1997, p. 320).

Assim, a aprendizagem é uma consequência e uma realidade devido às relações interpessoais que o indivíduo experimenta. Essas relações interpessoais se dão na enunciação, conceito este que se refere ao todo onde se manifesta o dialogismo; não apenas envolve a linguagem verbal, mas, também, outros signos de natureza não verbal. Para Bakhtin (2006, p. 320), é na enunciação que reside o tema (sentido), e não, propriamente, nas palavras: “[...] o tema da enunciação é determinado não só pelas formas linguísticas que entram na composição 
(as palavras, as formas morfológicas ou sintáticas, os sons, as entoações), mas igualmente pelos elementos não verbais da situação".

Os elementos não verbais que estão relacionados às manifestações verbais, e aos quais Bakhtin (2006, p. 41) se refere, são os demais tipos de manifestação e de interação de natureza semiótica, como: a mímica, a linguagem gestual, os gestos condicionados, entre outros. Sendo assim, os variados signos envolvidos na enunciação formatam o sentido das coisas. Para o autor, a construção de significados se manifesta e ocorre por meio do material semiótico, ou seja, ocorre mediada pelos signos, de forma que a aprendizagem consistiria em um diálogo entre os signos já internalizados e os signos presentes na situação de aprendizagem. Segundo Bakthin (2006, p. 32):

[...] o signo se opõe ao signo, que a própria consciência só pode surgir e se afirmar como realidade mediante a encarnação material em signos. Afinal, compreender um signo consiste em aproximar o signo apreendido de outros signos já conhecidos; em outros termos, a compreensão é uma resposta a um signo por meio de signos.

Bakhtin (2006) ainda afirma que uma enunciação, para ser completa, é composta por temas, e, também, por significações. A integração desses elementos forma um todo. Resumidamente, o tema ou sentido pode ser definido como a parte mais específica de uma palavra, que está, essencialmente, relacionada a um contexto dialógico, ou seja, é o que uma palavra (ou um sinal de uma língua de sinais) assume em função de um contexto, construindo-se na compreensão ativa e responsiva entre os interlocutores. O tema não está no locutor ou no interlocutor, nem mesmo na palavra, está na interação entre os indivíduos, e é produzido nessa interação envolvendo não somente signos linguísticos, mas, também, outros, como os visuais. Assim, é na interação que ocorre a produção do sentido, ou o chamado tema da enunciação. Por outro lado, há a significação, que também se conecta aos signos e permite a interpretação de um contexto. A significação é a parte mais geral e abstrata de uma palavra. São os significados que a palavra possui mais comumente, e, assim, o que se tem listado nos dicionários são as significações das palavras. $\mathrm{Na}$ enunciação, os elementos que se repetem, e nessas repetições são idênticos, constituem a significação.

Em um resumo destas ideias de Bakhtin (2006), podemos dizer que a construção de conhecimento é mediada pela linguagem, a qual, além de envolver os signos linguísticos - como as palavras e os sinais presentes em um contexto bilíngue com a Língua Portuguesa e a Libras -, também envolve os demais signos não verbais, que ajudam a construir um tema da enunciação. Em contextos bilíngues de aprendizagem, como em qualquer outro contexto de aprendizagem, espera-se que um tema seja alcançado, ou seja, que todos os integrantes da sala de aula (professor, intérprete/interlocutor e alunos) dialoguem em direção a um sentido científico-escolar para os conceitos e conteúdos tratados. Para isso, com base nas ideias do autor, podemos assumir que o compartilhamento de significado tendo como orientação o conhecimento científico-escolar consiste em uma exigência para o desenvolvimento de aprendizagens. Com base nestas considerações e nas ideias de Bakhtin, apresentamos algumas discussões nos subtópicos que se seguem. 


\section{Entre as significações e os significados físicos: um olhar sobre os termos dicionarizados}

O intérprete de Libras e o interlocutor de Libras, assim como um tradutor de línguas orais, apresentam enunciados utilizando termos (sinais) que julgam serem adequados para transmitir um sentido original. No entanto, segundo o que apresentamos anteriormente, nos dois momentos em que o interlocutor apresentou, em Libras, os enunciados sobre velocidade e aceleração, alguns dos sinais utilizados possuíam significados mais frequentes no uso cotidiano (significações) que divergiam do significado científico-escolar.

Um interlocutor de Libras, não especialista em uma disciplina científica como a Física, pode selecionar os termos segundo o significado que ele próprio assume para o termo original, o qual, muitas vezes, coincide com a significação, ou seja, com o significado comum listado nos dicionários. Neste sentido, para melhor entender as escolhas feitas pelo interlocutor ao apresentar, em Libras, os enunciados, estendemos nossa análise a partir de um levantamento de termos dicionarizados de Libras que possuem uma correspondência com os termos da língua portuguesa utilizados na explicação dos conceitos de velocidade e aceleração.

A partir dos dois enunciados explicativos dos conceitos que serviram de base para o nosso estudo de caso, verificamos, em dicionários de Libras, os principais termos utilizados nos enunciados; termos estes que assumem um papel importante na definição dos conceitos de velocidade e aceleração, sendo seu entendimento correto um componente necessário para a aprendizagem em Física.

Com o levantamento, buscamos identificar possíveis divergências de significado entre os termos de Libras dicionarizados e seus correlatos na língua portuguesa. O levantamento dos termos dicionarizados foi feita a partir de três dicionários de Libras: o Dicionário da Lingua Brasileira de Sinais, desenvolvido no âmbito de um projeto apoiado pela Coordenação Nacional de Deficiência (LIRA; SOUZA, 2008); o Dicionário de Libras ilustrado, elaborado com apoio do programa Acessa São Paulo de Inclusão Digital (SÃO PAULO, 2002); e o Dicionário enciclopédico ilustrado trilíngue de Lingua de Sinais Brasileira (Libras) baseado em linguistica e neurociência cognitiva (CAPOVILLA; RAFHAEL; MAURICIO, 2009). Tais dicionários são amplamente divulgados entre os intérpretes e interlocutores de Libras. Os dois primeiros são disponibilizados no formato multimídia, em que são apresentadas - além do sinal na forma de vídeo e seu correspondente na língua portuguesa escrita - suas significações mais usuais na cultura surda. Já no terceiro dicionário, o qual está disponível na forma de livro, os sinais são apresentados por descrições do movimento espacial das mãos que deve ser feito, e, em alguns casos, os movimentos são também representados por desenhos. O dicionário também apresenta a significação de cada sinal na língua portuguesa escrita. Nos três dicionários, há, ainda, exemplos de frases no português escrito com os termos relacionados aos sinais.

Neste levantamento, estão incluídos todos os sinais apresentados pelo interlocutor e que identificamos, anteriormente, com um número entre parênteses. O sinal 16, utilizado frequentemente pelo interlocutor para representar a palavra aceleração, não foi encontrado nos três dicionários consultados. No entanto, reconhecemos como sendo o sinal para o termo "aceleração", proposto pelo vocabulário de mecânica do projeto Sinalizando a Física (CAR- 
DOSO; BOTAN; FERREIRA, 2010), organizado por um grupo da Universidade Federal de Mato Grosso. Assim, em nosso levantamento, também incluímos o sinal 16, e apresentamos a significação segundo o vocabulário de mecânica em questão.

A seguir, no Quadro 1 e no Quadro 2, apresentamos os resultados do levantamento, com alguns comentários. Nos quadros, os números na coluna "Significação de seu correlato em Libras" indicam os sinais em Libras existentes para o termo nos dicionários consultados. Cada número corresponde a um sinal em Libras diferente, que está relacionado a um determinado termo da língua portuguesa. Por exemplo, para o termo "corpo", existem quatro sinais diferentes identificados pelos números 2, 3, 4 e 5, e cada um representa uma ou mais significações, as quais também são apresentadas. A numeração é a mesma apresentada no Apêndice ao final do artigo, o qual descreve o modo de apresentar cada um dos sinais presentes em nosso levantamento e identificados na transcrição do que foi apresentado pelo interlocutor.

Nos quadros, algumas das significações apresentadas são idênticas para diferentes sinais, sendo indicado com a expressão “idem a...”. Além da numeração, são apresentadas letras à frente de cada número, as quais indicam em qual dos dicionários consultados foi encontrado a significação para o verbete. A letra "a" se refere ao Dicionário da Lingua Brasileira de Sinais, a letra "b" se refere ao Dicionário de Libras ilustrado, a letra "c" se refere ao Dicionário enciclopédico ilustrado trilingue de Lingua de Sinais Brasileira (Libras) baseado em linguistica e neurociência cognitiva, e a letra "d" se refere ao vocabulário de mecânica do projeto Sinalizando a Física. Em alguns casos, o mesmo sinal é apresentado em mais de um dicionário. Por exemplo, para o termo "corpo", o sinal indicado pelo número 2 está presente em dois dicionários, e, assim, é indicado com a letra referente a cada um, no caso, $2 \mathrm{a}$ e $2 \mathrm{c}$.

A partir do levantamento apresentado no Quadro 1, percebe-se que, para cada um dos termos utilizados nos enunciados, há, no mínimo, um sinal de Libras. Entretanto, percebe-se, também, que o compartilhamento de significado entre o apresentado nos dicionários e a noção científica não ocorre para todos os sinais. Em relação ao termo "aceleração", excetuando-se a significação para o sinal 16d, que foi retirada de um vocabulário em Libras específico de conceitos físicos, seu correlato mais próximo em Libras possui um sentido parcialmente correto do ponto de vista científico. Nos três dicionários consultados ( $a$; b; c), o termo "aceleração" ou o seu correspondente na forma verbal (acelerar) possuem uma significação relacionada ao aumento de velocidade durante certo tempo, porém, este termo, em um contexto científico, é utilizado, também, para uma diminuição de velocidade em um intervalo de tempo. Na realidade, esta incompletude na significação apenas retrata uma compreensão comum deste termo quando empregado no cotidiano, algo já bem conhecido, há algum tempo, na literatura em ensino de ciências (LABURÚ, 1987).

Conforme se observa no Quadro 1, há também a indicação de um mesmo sinal (13), por dicionários diferentes, para designar os termos "aceleração" e "velocidade". Enquanto dois dicionários (a; c) apresentam o sinal 13 como correspondente ao termo "velocidade", outro dicionário (b) apresenta o mesmo sinal como relacionado ao termo "aceleração". Isso poderia sugerir que não há diferenciação clara entre estes termos na Libras.

Vale destacar que essa não diferenciação clara de sinais para os termos "velocidade" e "aceleração" também esteve presente na interpretação em Libras do participante de nosso estudo. Conforme apresentamos anteriormente, no primeiro momento em que o interlocutor apresentou os enunciados em Libras, ele utilizou um mesmo sinal, identificado com o número 
Quadro 1. Termos da língua portuguesa e a significação em seus correlatos em Libras

\begin{tabular}{|c|c|c|}
\hline Termo & $\begin{array}{c}\text { Significado do termo } \\
\text { quando utilizado no ensino de Física }\end{array}$ & $\begin{array}{l}\text { Significação de seu correlato } \\
\text { em Libras }\end{array}$ \\
\hline Posição & $\begin{array}{l}\text { Ponto espacial onde se localiza } \\
\text { determinado corpo }\end{array}$ & $\begin{array}{l}\text { 1a- Postura do corpo (da pessoa); pose; } \\
\text { atitude; } \\
\text { 1c- Maneira de colocar o corpo ou parte } \\
\text { do corpo; postura. }\end{array}$ \\
\hline Corpo & $\begin{array}{l}\text { Objeto que possui massa e ocupa uma } \\
\text { posição no espaço }\end{array}$ & $\begin{array}{l}\text { 2a- A substância física de cada homem } \\
\text { ou animal; } \\
\text { 2c- A parte material ou a carne de um ser } \\
\text { humano (ou animal não humano), que é } \\
\text { distinta da alma e do espirito; A estrutura } \\
\text { física e biológica do ser humano ou do } \\
\text { animal que se divide em três partes: } \\
\text { cabeça, tronco e membros; o tronco, tal } \\
\text { como distinto da cabeça e membros. } \\
\text { 3b- Estrutura física de um organismo; } \\
\text { parte material dos seres; } \\
\text { 3c- Idem a } 2 c \text {; } \\
\text { 4c- Idem a } 2 c ; \\
\text { 5c- Idem a } 2 c .\end{array}$ \\
\hline Deslocamento & Variação da posição de um corpo & 6b- Mudar de um lugar para outro. \\
\hline
\end{tabular}

continua

16, para representar ambos os termos. Já no segundo momento em que o interlocutor participante apresentou os enunciados em Libras, conforme também já expomos, apesar de ele utilizar, na maioria das vezes, um sinal diferente - o que, no contexto de sala de aula, facilitaria o reconhecimento de dois termos e conceitos diferentes para os sinais escolhidos (sinal 16 para "aceleração" e sinal 15 para "velocidade") -, mantém-se pouca clareza entre os termos segundo as significações presentes nos dicionários, o que poderia limitar o uso "mais científico" dos termos em contextos diferentes da sala de aula.

Esta distinção pouco clara dos sinais em Libras correlatos dos termos se apresenta como um problema. Primeiro, e conforme já comentamos, pode representar uma falta de clareza sobre a diferença existente entre os conceitos de velocidade e aceleração dentro da própria comunidade que utiliza Libras, incluindo os intérpretes e interlocutores. Neste sentido, ao mesmo tempo em que qualquer sinal apresentado nos dicionários poderia ser aceito como adequado por um intérprete ou por um interlocutor que não diferencia claramente os conceitos, para um intérprete ou interlocutor que sabe diferenciá-los claramente, escolher qual sinal utilizar não é uma tarefa fácil. Segundo, mesmo havendo em uma situação de ensino e aprendizagem um uso distinto de sinais para cada conceito, o que nos leva a definir, nas palavras de Bakhtin (2006), 
Quadro 1. continuação

\begin{tabular}{|c|c|c|}
\hline Termo & $\begin{array}{c}\text { Significado do termo } \\
\text { quando utilizado no ensino de Física }\end{array}$ & $\begin{array}{l}\text { Significação de seu correlato } \\
\text { em Libras }\end{array}$ \\
\hline Movimento & $\begin{array}{l}\text { Mudança de posição de um corpo ou } \\
\text { ponto material em um determinado } \\
\text { tempo, medido por um observador } \\
\text { inercial }\end{array}$ & $\begin{array}{l}\text { 7a- Circulação; afluência de gente; agitação; } \\
\text { 7c- Qualidade que resulta de grande } \\
\text { quantidade de gente ou veículos em ir-e-vir } \\
\text { incessante, agitação, alvoroço, confusão. } \\
\text { 8c- tipo de deslocamento em que o que } \\
\text { se desloca possui velocidade e direção, } \\
\text { a qual pode mudar ou não ao longo do } \\
\text { movimento. }\end{array}$ \\
\hline Tempo & $\begin{array}{l}\text { Sem uma definição formal. } \\
\text { Relacionado a uma duração de um } \\
\text { evento ou fenômeno, que pode ser } \\
\text { expresso na forma de horas, minutos, } \\
\text { segundos etc. }\end{array}$ & $\begin{array}{l}\text { 9a- Período que se expressa em minutos e } \\
\text { horas; Estado meteorológico da atmosfera; } \\
\text { temperatura; } \\
\text { 9c- Dimensão responsável pela } \\
\text { transformação dos seres e das coisas ao } \\
\text { longo do ciclo de suas vidas e existências, e } \\
\text { que pode ser dividida em unidades como: } \\
\text { segundo, minuto, hora, dia, semana, mês, } \\
\text { ano, século, milênio etc.; Duração; Época. } \\
\text { 10a- Um intervalo; uma pausa; } \\
\text { 10b- Pedir tempo em jogos esportivos; } \\
\text { 10c- Pedir tempo, pausa. } \\
\text { 11c- Condição meteorológica da atmosfera; } \\
\text { Clima. } \\
\text { 12c- Época; Era; Período de tempo no } \\
\text { passado; passado. }\end{array}$ \\
\hline Velocidade & $\begin{array}{l}\text { Quanto um corpo se desloca por } \\
\text { unidade de tempo. }\end{array}$ & $\begin{array}{l}\text { 13a- Relação entre um espaço percorrido e } \\
\text { o tempo gasto no percurso; } \\
\text { 13c- Relação entre espaço percorrido } \\
\text { e tempo de percurso, no movimento } \\
\text { uniforme; Movimento ou deslocamento } \\
\text { rápido ou apressado. }\end{array}$ \\
\hline
\end{tabular}

continua

como sendo possível que se desenvolva um tema para a enunciação que poderia se aproximar do esperado no contexto científico-escolar, não é garantido que o compartilhamento de sentido seja alcançado em diálogos posteriores com a presença de novos indivíduos, os quais não estiveram na mesma situação de ensino e aprendizagem (professores, alunos, intérpretes/ interlocutores, família, amigos etc.). 
Quadro 1. continuação

\begin{tabular}{|c|c|c|}
\hline Termo & $\begin{array}{l}\text { Significado do termo } \\
\text { quando utilizado no ensino de Física }\end{array}$ & $\begin{array}{c}\text { Significação de seu correlato } \\
\text { em Libras }\end{array}$ \\
\hline Aceleração & $\begin{array}{l}\text { Quanto um corpo aumenta ou diminui } \\
\text { (varia) sua velocidade por unidade de } \\
\text { tempo. }\end{array}$ & $\begin{array}{l}\text { 13b- Apressar o ritmo com que algo ou } \\
\text { alguém executa uma ação; aumentar a } \\
\text { velocidade. } \\
\text { 14a- Pressionar o pedal do acelerador de um } \\
\text { veículo, aumentando sua velocidade; } \\
\text { 14c- Imprimir maior velocidade ao veículo, } \\
\text { mediante aceleração progressiva do motor. } \\
\text { 15a- Apressar; aumentar o ritmo; } \\
\text { 15c- Idem a 14a. } \\
\text { 16d- Grandeza vetorial que indica a variação } \\
\text { da velocidade de um móvel por unidade de } \\
\text { tempo.. } \\
\text { (Nos itens marcados com as letras "a" } e \text { "b", } \\
\text { o substantivo "aceleração" não foi encontrado, } \\
\text { mas, sim, seu correspondente na forma verbal: } \\
\text { "acelerar"). }\end{array}$ \\
\hline
\end{tabular}

Fonte: Elaborado pelos autores

Em relação aos termos "posição" e "corpo", as significações apresentadas no Quadro 1 não coincidem com a descrição do conceito físico. Conforme já expusemos ao comentarmos a interpretação destes termos pelo interlocutor, isto implicaria a necessidade de atribuição de um novo significado ao sinal em Libras, ou, mesmo, a substituição do sinal por outro que seja sinônimo e que possua uma significação mais próxima da noção científica. Considerando este último caso, os sinônimos para os termos "Posição" e "Corpo" presentes na língua portuguesa, respectivamente "Local" e "Objeto", foram verificados nos dicionários de Libras. O Quadro 2 apresenta a significação dos sinônimos. Neste, os números e letras na última coluna indicam o mesmo do Quadro 1: números diferentes indicam sinais diferentes e as letras indicam em qual dicionário o sinal foi encontrado.

Considerando os sinônimos, verificou-se que, para os termos "posição" e "corpo", existem representações em Libras que se aproximam mais da descrição do conceito físico. Ressalta-se, no entanto, que, apesar do uso de sinônimos ser uma possibilidade, a atribuição de significados a termos é algo comum em qualquer diálogo, às vezes ocorrendo de forma até mesmo não explícita. Nas aulas de Física, a atribuição de significados ocorre, por exemplo, quando se trata dos conceitos de peso e calor, termos que, no cotidiano, assumem comumente outros significados diferentes dos significados da Física. Assim, uma explicação de um professor que busca diferenciar termos empregados na ciência do seu emprego no cotidiano é um exemplo de busca pela atribuição de significado. Esta atribuição de significados científicos aos termos é uma das funções de um professor, é algo inerente ao ato de ensinar, independente de o professor 
Quadro 2. Termos da língua portuguesa e a significação dos correlatos do sinônimo em Libras

\begin{tabular}{|l|l|l|l|}
\hline Termo & Sinônimo & $\begin{array}{l}\text { Significado do termo quando } \\
\text { utilizado no ensino de Física }\end{array}$ & \multicolumn{1}{|c|}{$\begin{array}{c}\text { Significação do correlato } \\
\text { do sinônimo em Libras }\end{array}$} \\
\hline Posição & Local & $\begin{array}{l}\text { Ponto espacial onde se localiza } \\
\text { determinado corpo }\end{array}$ & $\begin{array}{l}\text { 17a- Lugar; localidade; ponto; } \\
\text { 17b- Qualquer área de tamanho limitado } \\
\text { ou não; } \\
\text { 17c- Lugar, localidade. }\end{array}$ \\
\hline Corpo & Objeto & $\begin{array}{l}\text { Objeto que possui massa e } \\
\text { ocupa uma posição no espaço }\end{array}$ & $\begin{array}{l}\text { 18a- Coisa material; o que é palpável, } \\
\text { tangível; } \\
\text { 18c- Tudo que é perceptível por qualquer } \\
\text { dos sentidos; coisa; peça; artigo de } \\
\text { compra e venda; coisa material, o que é } \\
\text { palpável, tangível. }\end{array}$ \\
\hline
\end{tabular}

Fonte: Elaborado pelos autores.

lecionar em uma turma com ou sem alunos com necessidades especiais. Neste sentido, caberá ao intérprete auxiliar tanto o professor como os alunos com deficiência auditiva e os alunos com surdez no processo de atribuição de significados a um termo, no caso, um sinal em Libras.

A partir do levantamento que apresentamos, podemos dizer que existem sinais em Libras que poderão ser mais adequados que outros para apresentar determinados termos da língua portuguesa que possuem um significado físico relacionado. Isto permite afirmar que o próprio intérprete ou interlocutor possui um papel importante na promoção da aprendizagem dos alunos que acompanha: é ele quem seleciona os sinais que devem ser mais adequados, é ele que poderá, inclusive, optar por sinais que correspondam a termos sinônimos em português aos termos científicos que não são contemplados com um sinal específico na Libras. Logicamente, a escolha adequada dos sinais, sejam eles sinônimos ou não, como a própria percepção do intérprete ou do interlocutor da necessidade de utilizar um ou outro sinal, só é possível se ele possui um conhecimento mínimo do conteúdo que interpreta, conhecimento este que vá ao encontro da perspectiva científica.

\section{Contexto dialógico e o compartilhamento de significados}

Em situações de tradução de enunciados, como é o caso de ambientes bilíngues de ensino e aprendizagem, alcançar o compartilhamento de significados, isto é, ter um tema comum para os diálogos que se estabelecem (se, de fato, são estabelecidos), constitui-se como um objetivo a ser alcançado em meio a este processo dinâmico e complexo de ensino e aprendizagem. Porém, é importante ressaltar a necessidade da manifestação dos alunos com deficiência auditiva e dos alunos com surdez, mediante o apoio do intérprete ou do interlocutor de Libras, para que se chegue ao almejado compartilhamento de significados compatíveis com o conhecimento científico-escolar. 
Ainda que neste estudo não tenhamos buscado analisar e caracterizar a participação de alunos com deficiência auditiva e alunos com surdez, afinal, nos centramos em uma análise de enunciados apresentados por um interlocutor, vale destacar que a participação ativa (e interativa) destes alunos é talvez a única forma pela qual o professor poderá reconhecer a assimilação do que se está sendo ensinado. Conforme afirma Bakhtin (2006), é na interação dialógica que o sujeito realiza aprendizagens.

De certa forma, a manifestação dos alunos como algo necessário em um processo de ensino e aprendizagem não é uma novidade, e encontra lugar em diferentes teorias de aprendizagem sócio-histórico-culturais. No caso específico de um contexto de aprendizagem bilíngue com atuação de um intérprete ou de um interlocutor, o que acaba sendo uma novidade é a função deste em intermediar os possíveis diálogos entre professor e alunos, o que, portanto, interfere tanto na assimilação dos alunos, como no reconhecimento, por parte do professor, se a aprendizagem é alcançada ou não para os alunos com deficiência auditiva e para os alunos com surdez.

E para que a aprendizagem ocorra, segundo o que temos discutido neste artigo, faz-se necessário o compartilhamento de significados, em que o intérprete ou o interlocutor tenha algum conhecimento do conteúdo que interpreta, e em que haja a manifestação do aluno com deficiência auditiva e do aluno com surdez, expondo o seu entendimento, ou seja, aquilo já internalizado relativo ao conteúdo. É na externalização daquilo que foi assimilado com base no conhecimento apresentado, na interação dialógica entre alunos e professor e com o apoio do intérprete ou do interlocutor de Libras, que o conhecimento científico é construído e tratado.

Reconhecemos que, em meio à dinâmica da sala de aula, independente de ela haver ou não alunos com necessidades especiais, não é tão simples a identificação de incompatibilidades de significado, e, muitas vezes, mesmo os alunos que não possuem uma necessidade especial não expõem suas ideias e construções. Porém, considerando que é na interação dialógica que está presente o sentido e é nesta interação que o sentido pode ser revelado, é inevitável afirmar que, para que a sala de aula seja inclusiva para os alunos com deficiência auditiva e para os alunos com surdez, são necessárias estratégias de ensino que privilegiem a manifestação destes alunos e, ainda, um planejamento que preveja a atuação do intérprete ou do interlocutor de Libras.

\section{Considerações finais}

Para finalizar este artigo, ressaltamos alguns pontos que julgamos serem centrais na análise que nos propomos a fazer. Primeiramente, podemos destacar a complexidade envolvida em um estudo como este, em que nos esforçamos para interpretar aspectos linguísticos inter -relacionando-os com outros aspectos de natureza científica e pedagógica. Tal complexidade é significativa, uma vez que a Libras é uma língua ainda em formação, em meio a um processo de crioulização (HOLM, 2000; SOUZA; SEGALA, 2009). Qualquer língua viva está em constante modificação, especialmente aquelas em processo de formação. Entre as modificações que ocorrem, destaca-se a inserção de novos termos na língua (neologismo) devido a vários fatores, como o uso de termos estrangeiros (modificando-os ou não na grafia e/ou na fonética), ou a modificação de termos por necessidade de alteração da função gramatical (por exemplo, modificação na grafia de um verbo dando origem a um substantivo). A Libras é uma língua que 
carece, ainda, de termos que possuam correlatos com algumas das palavras de uma língua com maior estabilidade, como a língua portuguesa, e, assim, constantemente surgem novos sinais. Além disso, possui alguns sinais que podem ser utilizados em funções gramaticais diferentes. Por exemplo, o sinal 6 apresentado no Quadro 1, referente ao substantivo "deslocamento", também é utilizado para o verbo "mudar" no sentido de alterar a posição.

Um aspecto que vale ser destacado, ainda que não tenha sido o nosso foco de investigação, se refere à visão que integrantes do contexto escolar possuem sobre a interpretação em Libras. A partir de conversas informais com professores da mesma escola em que o interlocutor participante atuava, identificamos uma percepção ingênua destes de que o que é interpretado em Libras seguramente mantém o significado do que se enuncia originalmente na Língua portuguesa. Em outras palavras, para os professores, bastaria que houvesse interpretação em Libras na sala de aula para que o aluno com surdez e o aluno com deficiência auditiva aprendessem. Esta visão ingênua foi confirmada em meio aos diálogos com o interlocutor participante, quem em uma postura crítica, reconheceu a mesma percepção em muitos dos professores com os quais trabalha. Em oposição a esta percepção, conforme verificamos, o compartilhamento de significado fica comprometido pelo entendimento que o intérprete ou interlocutor possui sobre as noções e conceitos envolvidos nos enunciados que interpreta. Tal situação nos leva a reafirmar a necessidade de um trabalho conjunto entre o professor e aquele que interpreta sua aula em Libras, de forma a permitir, ao intérprete ou ao interlocutor, uma melhor compreensão do conteúdo científico-escolar que interpreta. Professor e intérprete/interlocutor necessitam planejar conjuntamente a situação de aula, ou, no mínimo, o professor deve esclarecer antecipadamente, ao intérprete ou ao interlocutor, o significado assumido pelos principais conceitos que serão ensinados, destacando a diferença entre estes e um possível sentido que possa ser assumido quando os termos relativos a tais conceitos são utilizados no senso comum.

Conforme descrevemos, o participante de nosso estudo fez um curso de formação de média duração (180 horas) e atuava profissionalmente como interlocutor há somente um ano. Sem dúvidas, o vocabulário em Libras conhecido pelo participante é reduzido, se comparado ao de um intérprete experiente que possui uma formação em Libras mais extensa, por exemplo, com um curso Superior de tradução e interpretação em Libras e língua portuguesa, ou que possui mais tempo de atuação em turmas de Física. A pouca experiência no trabalho em uma escola regular e em interpretar tópicos de Física acaba por limitar a atuação do interlocutor. Entretanto, como o processo de inclusão é ainda recente e como a formação de intérpretes não engloba conceitos específicos de Física, acreditamos que, mesmo no caso de um intérprete de Libras experiente, seria limitada a sua atuação, e não seria garantido o compartilhamento de significados, caso não haja um trabalho conjunto adequado com o professor.

É importante destacar que independente da aparente pouca experiência do interlocutor participante do estudo, este atuava legalmente em uma escola pública, e os integrantes do contexto escolar, incluindo os professores e os alunos com surdez e deficiência auditiva, o reconheciam como aquele que interpretava, em Libras, as exposições, questionamentos e comentários que ocorriam nas aulas. Além disso, foi perceptível o seu empenho em desenvolver bem a sua função. Ao comentar isto, não entramos no mérito da discussão sobre o que é ser ou não um intérprete ou um interlocutor profissional, mas afirmamos que, independente de definições formais próprias das comunidades de intérpretes ou previstas nas legislações vigentes, o participante era reconhecido, na instituição escolar, como aquele que intermediaria a comunicação na sala de 
aula entre os professores e os alunos surdos e os alunos com deficiência auditiva, sendo visto, assim, como ocupando um papel importante na desejável sala de aula inclusiva.

Por fim, destacamos que nosso objetivo neste estudo não foi o de efetuar qualquer julgamento sobre o interlocutor participante. Em conversas com o mesmo e no acompanhamento de seu trabalho em sala de aula, que ocorreu atendendo outros objetivos não relacionados diretamente ao que apresentamos neste artigo, ficou claro, aos pesquisadores, o seu empenho e dedicação em seu trabalho como interlocutor. Mas, considerando sua pouca experiência e, segundo ele, a não possibilidade, muitas vezes, de ocorrer um trabalho conjunto com os professores, os resultados que apresentamos nos levam a afirmar que os alunos com deficiência auditiva e os alunos com surdez atendidos pelo interlocutor poderiam, muitas vezes, se encontrar em situação de exclusão acadêmica, isto é, sem condições de aprender juntamente com a turma.

\section{Referências}

BAKHTIN, M. M. Bakhtin, marxismo e filosofia da linguagem. 12. ed. São Paulo: Hucitec, 2006.

BRASIL. Constituição (1988). Constituição da República Federativa do Brasil. Brasília: Senado Federal, 1988.

. Decreto legislativo $n^{\circ} 186$, de 2008. Aprova o texto sobre os direitos das pessoas com deficiência e de seu protocolo facultativo, assinados em Nova Iorque, em 30 de março de 2007. Diário Oficial da União, Brasília, 10 jul. 2008. Disponível em: <http:/ /www. planalto.gov.br/ccivil_03/constituicao/congresso/DLG/DLG-186-2008.htm>. Acesso em: 08 fev. 2015.

Decreto $N^{\circ}$ 5.626, de 22 de dezembro de 2005. Regulamenta a lei n ${ }^{\circ} 10.436$, de 24 de abril de 2002, que dispõe sobre a Língua Brasileira de Sinais - Libras, e o art. 18 da lei no 10.098, de 19 de dezembro de 2000. Diário Oficial da União, Brasília, 23 dez. 2005. Disponível em: <http://www.planalto.gov.br/ccivil_03/_ato2004-2006/2005/decreto/ d5626.htm>. Acesso em: 08 fev. 2015.

Lei $\mathrm{N}^{\circ}$ 9.394, de 20 de dezembro de 1996. Estabelece as diretrizes e bases da educação nacional. Diário Oficial da União, Brasília, 23 dez. 1996. Disponível em: <http://www.planalto.gov.br/ccivil_03/leis/19394.htm>. Acesso em: 08 fev. 2015.

. Lei n ${ }^{\circ} 10.436$, de 24 de abril de 2002. Dispõe sobre a Língua Brasileira de Sinais Libras e dá outras providências. Diário Oficial da União, Brasília, 25 abr. 2002. Disponível em: <http://www.planalto.gov.br/ccivil_03/leis/2002/110436.htm>. Acesso em: 08 fev. 2015.

. Lei $\mathrm{n}^{\mathrm{o}} 12.319$, de $1^{\circ}$ de setembro de 2010. Regulamenta a profissão de tradutor e intérprete da Língua Brasileira de Sinais - LIBRAS. Diário Oficial da União, Brasília, 02 set. 2010a. Disponível em: <http://www.planalto.gov.br/ccivil_03/_Ato2007-2010/2010/ Lei/L12319.htm>. Acesso em: 08 fev. 2015. 
$\frac{\text { 2010b. }}{\text {. Ministério da Educação. Mensagem n }}{ }^{\mathbf{o}} 352$ de $1^{\text {o }}$ de setembro de 2010. Brasília,

- Ministério da Educação. Conselho Nacional de Educação. Diretrizes nacionais para a educação especial na educação básica. Parecer no 17/2001 aprovado em 03/07/2001. Brasília, 2001. Disponível em: <http://portal.mec.gov.br/cne/arquivos/pdf/ CEB017_2001.pdf>. Acesso em: 08 fev. 2015.

. Ministério da Educação. Secretaria de Educação Especial. Política nacional de educação especial na perspectiva da educação inclusiva. Brasília, 2007. Disponível em: $<$ http://peei.mec.gov.br/arquivos/politica_nacional_educacao_especial.pdf > . Acesso em: 08 fev. 2015.

. Saberes e práticas da inclusão: desenvolvendo competências para o atendimento às necessidades educacionais especiais de alunos surdos. Brasília, 2006. Disponível em: <http://portal.mec.gov.br/seesp/arquivos/pdf/alunossurdos.pdf>. Acesso em: 08 fev. 2015. CAPOVILLA, F. C.; RAFHAEL, W.; MAURICIO, A. C. Dicionário enciclopédico ilustrado trilíngue de Língua de Sinais Brasileira (Libras) baseado em linguística e neurociência cognitiva. São Paulo: Edusp, 2009. 2 v.

CARDOSO, F. C.; BOTAN, E.; FERREIRA, M. R. Sinalizando a Física 1: vocabulário de mecânica. Sinop: UFMT, 2010. v. 1.

COSTA, M. P. R. Compreendendo o aluno portador de surdez e suas habilidades comunicativas. In: MAGALHÃES, R. C. (Org.). Reflexões sobre a diferença: uma introdução à educação especial. 2. ed. Fortaleza: Edições Demócrito rocha, 2003. p. 125-134. FREITAS, M. T. A. Nos textos de Bakhtin e Vygotsky: um encontro possível. In: BRAIT, B. (Org.). Bakhtin, dialogismo e construção do sentido. Campinas: Editora Unicamp, 1997. p. 311-330.

GESSER, A. Libras? Que língua é essa?: crenças e preconceitos em torno da língua de sinais e da realidade surda. São Paulo: Parábola, 2009.

HOLM, J. A. An introduction to pidgins and creoles. Cambridge: Cambridge University Press, 2000.

LABURÚ, C. E. Desenvolvimento e aprendizagem do conceito de aceleração em adolescentes. 1987. 288 f. Dissertação (Mestrado em Ensino de Ciências) - Programa Interunidades Intituto de Física, Faculdade de Educação, Instituto de Química, Universidade de São Paulo, São Paulo, 1987.

LIRA, G. A.; SOUZA,T. A. F. Dicionário da Língua Brasileira de Sinais: versão 2.1. 2008. Disponível em: <http://www.acessobrasil.org.br/libras/>. Acesso em: 10 jul. 2013.

RODRIGUES, D. Dez idéias (mal)feitas sobre a educação inclusiva. In: . (Org.).

Inclusão e educação: doze olhares sobre a educação inclusiva. São Paulo: Summus Editorial, 2006. p. 299-318. 
SÃO PAULO (Estado). Resolução SE - 38, de 19-6-2009. Dispõe sobre a admissão de docentes com qualificação na Língua Brasileira de Sinais - Libras, nas escolas da rede estadual de ensino. 2009. Disponível em: <http://siau.edunet.sp.gov.br/ItemLise/arquivos/38_09. HTM>. Acesso em: 08 fev. 2015.

. Secretaria de Gestão Pública. Dicionário de Libras ilustrado. São Paulo, 2002. 1 CD-ROM. (Programa Acessa São Paulo).

SILVA, O. H. M.; LABURÚ, C. E.; NARDI, R. Reflexões para subsidiar discussões sobre o conceito de calor na sala de aula. Caderno Brasileiro de Ensino de Física, Florianópolis, v. 25, n. 3, p. 383-396, dez. 2008. Disponível em: <https://periodicos.ufsc.br/index.php/ fisica/article/viewFile/9076/8458>. Acesso em: 08 fev. 2015.

SOUZA, R. B.; SEGALA, R. R. A perspectiva social na emergência das línguas de Sinais: a noção de comunidade de fala e idioleto segundo o modelo teórico laboviano. In: QUADROS, R. M.; STUMPF, M. R. (Org.). Estudos surdos IV. Petrópolis: Arara Azul, 2009. p. 21-48. Disponível em: < http://www.librasgerais.com.br/materiais-inclusivos/ downloads/Estudo-Surdos-IV-SITE.pdf>. Acesso em: 08 fev. 2015.

TEIXEIRA, S. K.; PACCA, J. L. A. O peso medido pela balança: ruptura e continuidade na construção do conceito. Caderno Brasileiro de Ensino de Física, Florianópolis, v. 11, n. 3, p. 154-171, 1994. Disponível em: <https://periodicos.ufsc.br/index.php/fisica/article/ view/7144>. Acesso em: 08 fev. 2015.

UNESCO. Declaração mundial sobre educação para todos: satisfação das necessidades básicas de aprendizagem. Jomtien, 1990. Disponível em: <http://unesdoc.unesco.org/ images/0008/000862/086291por.pdf>. Acesso em: 08 fev. 2015.

Declaración de Salamanca y marco de acción para las necesidades educativas especiales. 1994. Disponível em: < http:/ / www.unesco.org/education/pdf/SALAMA_S. PDF>. Acesso em: 09 fev. 2015. 


\section{Apêndice. Descrição dos sinais destacados}

1 (posição) - Mão horizontal fechada com a palma para trás e o dedo indicador e polegar distendidos na altura do rosto. Mover a mão para baixo até o peito;

2 (corpo) - Mãos em 1 com as palmas para trás na altura dos ombros. Movê-las para baixo virando os indicadores para baixo;

3 (corpo) - Mãos em L horizontal com as palmas para trás e diante do peito. Movê-las para baixo;

4 (corpo) - Mãos horizontais abertas, com as palmas para trás, tocando a parte superior do peito.

Movê-las para baixo;

5 (corpo) - Mãos horizontais abertas com as palmas para trás. Tocar a mão direita na altura do peito e mão esquerda na altura da barriga. Alternar as mãos e tocar a direita na barriga e a esquerda no peito; 6 (deslocamento) - Cada mão com seus dedos juntos, com as palmas para baixo. Mãos colocadas à direita do corpo. Mover as mãos para a esquerda do corpo com um movimento ligeiramente parabólico com a concavidade da parábola para baixo. Quando as mãos estiverem à esquerda, abri-las mantendo a palma delas para baixo.

7 (movimento) - Mão abertas com as palmas para baixo e os dedos separados, mão direita atrás da esquerda. Movê-las ligeiramente para frente e para trás, balançando os dedos;

8 (movimento) - Mão esquerda em 1 com a palma para a direita; mão direita em 1 com a palma para baixo e indicador apontado para a base do indicador esquerdo. Girar a mão direita no sentido antihorário num círculo horizontal para a esquerda;

9 (tempo) - Mão esquerda fechada com a palma para baixo; mão direita em 1 com a palma para baixo. Tocar a ponta do dedo indicado no pulso esquerdo;

10 (tempo) - Mão esquerda aberta com a palma para baixo. Tocar as pontas dos dedos direitos na palma esquerda;

11 (tempo) - Mão aberta com a palma para frente e os dedos curvados. Virar a palma para trás;

12 (tempo) - Mão vertical aberta, com a palma para trás, e ao lado da cabeça. Dobrar a palma para baixo. Balançar a mão para frente e para trás;

13 (velocidade/aceleração) - Mão aberta com a palma para cima. Balançá-la pelo pulso para a esquerda e para a direita;

14 (aceleração) - Mãos verticais abertas com as palmas para frente, inclinadas para baixo, lado a lado. Mover a mão direita diagonalmente para frente e para baixo;

15 (aceleração) - Mão em C com a palma para a esquerda. Movê-la rapidamente para a esquerda e para a direita, diante da boca;

16 (aceleração) - Mão direita estendida na horizontal com a palma para cima. Mover a mão para a esquerda, fechando-a gradativamente do dedo mínimo até o indicador;

17 (local) - Mãos horizontais fechadas, palma a palma, com os indicadores e polegares curvados formando a letra C, próximas uma da outra. Movê-las para baixo;

18 (objeto) - Mãos em 1, com as palmas para baixo e os indicadores inclinados um para o outro.

Mover as mãos alternadamente para baixo e para cima, tocando os indicadores. Após, as mãos devem estar em $\mathrm{V}$ horizontal em polegares distintos com as palmas para trás. Movê-las para os lados opostos, enquanto balança alternadamente os dedos médios e indicadores.

Artigo recebido em 07/09/13. Aceito em 18/07/14. 